\title{
Tuning $\mathrm{CH}_{3} \mathrm{NH}_{3} \mathrm{~Pb}\left(\mathrm{I}_{1-\mathrm{x}} \mathrm{Br}_{\mathrm{x}}\right)_{3}$ Perovskite Oxygen Stability in Thin Films and Solar Cells
}

\author{
Sebastian Pont, ${ }^{a}$ Daniel Bryant,,${ }^{a, b}$ Chieh-Ting Lin, ${ }^{a}$ Nicholas Aristidou, ${ }^{a}$ Scot \\ Wheeler, ${ }^{a}$ Xuerui Ma, ${ }^{a}$ Robert Godin, ${ }^{a}$ Saif A. Haque ${ }^{a}$ and James R. Durrant. ${ }^{a}, b^{*}$
}

\begin{abstract}
The rapid development of organic-inorganic lead halide perovskites has resulted in high efficiency photovoltaic devices. However the susceptibility of these devices to degradation under environmental stress has so far hindered commercial development, requiring for example expensive device encapsulation. Herein, we have investigated the stability of $\mathrm{CH}_{3} \mathrm{NH}_{3} \mathrm{~Pb}\left(l_{1-x} \mathrm{Br}_{\mathrm{x}}\right)_{3}[\mathrm{x}=0 . .1]$ thin film and solar cells under controlled humidity, light, and oxygen conditions. We show that higher bromide ratios increases tolerance to moisture, with $\mathrm{x}=1$ thin films being stable to $120 \mathrm{hr}$ of moisture stress. Under light and dry air, partial bromide $(x<1)$ subsitution does not enhance film stability significantly, with the corresponding solar cells degrading within two hours. In contrast $\mathrm{CH}_{3} \mathrm{NH}_{3} \mathrm{PbBr}_{3}$ films show excellent stability, with device stability being limited by the organic interlayer. For these $x=1$ films we show charge carriers are quenched in the presence of oxygen and form superoxide; however in contrast to perovskites containing iodide, this superoxide does not degrade the crystal. Our observations show that iodide limits the oxygen and light stability of $\mathrm{CH}_{3} \mathrm{NH}_{3} \mathrm{~Pb}\left(\mathrm{I}_{1-x} \mathrm{Br}_{\mathrm{x}}\right)_{3}$ perovskites, but that $\mathrm{CH}_{3} \mathrm{NH}_{3} \mathrm{PbBr}_{3}$ provides an opportunity to develop inherently stable high voltage photovoltaic devices and 4-terminal tandem solar cells.
\end{abstract}

\section{Introduction}

Since their breakthrough in 2012, hybrid organicinorganic lead halide perovskite solar cells (PSCs) have rapidly established themselves as a promising printable photovoltaic technology. ${ }^{1-6}$ Interest has been triggered by their certified efficiencies of $>20 \%$, ability to be solution processed, fabricated on flexible substrates and inherent low cost. ${ }^{4,7}$ While high efficiency and ease of processing make PSCs attractive as a next generation photovoltaic technology, issues regarding their instability remain a key challenge for commercialisation. Successful stability studies over $1000 \mathrm{hr}$ have already been demonstrated, however these studies have typically employed rigid glass encapsulation or dark testing conditions. ${ }^{7-13}$ The stability of unencapsulated device performance exposed to operating environmental stresses has not been investigated with as much detail. Herein we analyse the tuning of methyl ammonium lead halide perovskite stability as a function of iodine/bromine substitution under humidity, oxygen and/or light exposure, and go on to show the promising potential for methyl ammonium lead bromide's stability under these stress conditions.

Currently flexible encapsulation technologies cannot match the protection of glass to prevent the ingress of environmental factors such as oxygen and humidity. ${ }^{14}$ This represent a challenge for PSC, where material sensitivity to ambient conditions can prevent achieving the required lifetimes with current flexible encapsulation barriers. Therefore, for PSC solar cells to develop as a flexible technology with current thin film encapsulation capabilities, it is important that the devices exhibit significant stability to extrinsic environmental stress, as well as being intrinsically stable in inert conditions. To date degradation pathways have been shown to occur on exposure to moisture, heat, ultraviolet light and, most recently, through the combination of light and oxygen. ${ }^{15,16}$ Progress of PSC stability has be made on the most commonly used methylammonium lead iodide $\left(\mathrm{CH}_{3} \mathrm{NH}_{3} \mathrm{Pbl}_{3}\right)$ by inclusion of hydrophobic cations in the photoactive layer to improve moisture resistance. ${ }^{12,17}$ However many challenges still remain to understand and improve the tolerance to other degradation pathways. ${ }^{18,19}$

PSCs employing a mixture of halide anions (iodide and bromide) have been gaining much attention not only from their high efficiency but also their improved resistance to moisture degradation. ${ }^{20}$ Some early work by Noh et al on methyl ammonium lead iodide/bromide devices showed small amounts of bromide addition improved tolerance to hydration when devices were exposed to conditions of $55 \%$ relative humidity $(\mathrm{RH}){ }^{20}$ However, this work only looked at lower concentrations of bromide and modest humidity levels, and was not undertaken at the operating condition of a solar cell, i.e. it was without light exposure, which is a common trend of stability results stated in literature to date. Recently we have shown that a combination of light and oxygen to be the dominant degradation mechanism in $\mathrm{CH}_{3} \mathrm{NH}_{3} \mathrm{Pbl}_{3}$ devices, with severe degradation occurring in less than two hours in some architectures..$^{21,22}$ Herein we investigate the effect of methyl ammonium lead iodide/bromide mixed perovskites on stability when exposed to humidity or light and oxygen with the aim of providing insights into the ability of 'ion tuning' to enhance film and device stability, to compliment the impressive results on ion tuning in enhancing PSC efficiency. ${ }^{7}$ We go on to show iodide inclusion in a mixed 
perovskite structure results in significant instability under light and oxygen conditions, whereas $\mathrm{CH}_{3} \mathrm{NH}_{3} \mathrm{Br}_{3}$ films and PSC's show promising stability, with device stability being primarily limited by the organic hole collection interlayer of the devices employed.

\section{Experimental Section}

\subsection{Film preparation}

Stock solutions of $\mathrm{CH}_{3} \mathrm{NH}_{3} \mathrm{Pbl}_{3}$ and $\mathrm{CH}_{3} \mathrm{NH}_{3} \mathrm{PbBr}_{3}$ were prepared by dissolving stoichiometric ratios of $\mathrm{PbX}_{2}$ and $\mathrm{CH}_{3} \mathrm{NH}_{3} \mathrm{X}_{3}(\mathrm{X}=\mathrm{I}, \mathrm{Br})$ in a DMSO and GBL solution (7:3) at $1.25 \mathrm{M}$ and stirred for $60 \mathrm{~min}$ at $50^{\circ} \mathrm{C}$ and room temperature, respectively. To obtain a range in $\mathrm{CH}_{3} \mathrm{NH}_{3} \mathrm{~Pb}\left(\mathrm{I}_{(1-x)} \mathrm{Br}_{\mathrm{x}}\right)_{3}$ stock solutions were combined with volumetric ratios. Thin film samples were prepared on glass using the anti-solvent technique adapted from a previously reported method. ${ }^{6}$ Glass was washed in soap, acetone, and 2-proanol followed by a 10 min oxygen plasma treatment. The perovskite precursor solution was coated using a spin coating procedure using two speeds where toluene was dripped onto the surface during the second step and then dried at $100^{\circ} \mathrm{C}$ post deposition. The resulting films had thicknesses of $236 \pm 7 \mathrm{~nm}$, as measured by alpha step 200 .

\subsection{Film environmental stability characterisation}

Stability analysis of thin film materials was done in a glovebox with an LED light, humidity control, and atmospheric control between nitrogen and dry air. The light source was calibrated to current match a $\mathrm{CH}_{3} \mathrm{NH}_{3} \mathrm{Pbl}_{3}$ device under an AM1.5 solar spectrum to obtain a 1 sun eqv LED intensity. The Bridgelux $4000 \mathrm{~K}$ LED spectrum covers the visible spectrum, with negligible UV. Dry air conditions were obtained from bottled gas of a nitrogen and oxygen mix, at $21 \%$ oxygen concentration (BOC 12-X). Optical characterisation of samples were monitored with a digital camera and the change in the average RGB output values was monitored against background values according to equ (1):

$$
\text { Optical degradation }=\frac{\left|\mathrm{RGB}_{\mathrm{t}}-R G B_{\mathrm{deg}}\right|}{\left|\mathrm{RGB}_{0}-\mathrm{RGB}_{\mathrm{deg}}\right|}
$$

Where $R G B_{t}$ is the average red-green-blue pixel value at time $t, R G B_{\text {deg }}$ is the fully degraded sample, and $R G_{0}$ is the initial value a $t=0$.

\subsection{Device fabrication}

Cells were manufactured following a previously reported procedure. ${ }^{6}$ In summary, FTO coated glass substrates were coated with compact $\mathrm{TiO}_{2}$ by spray pyrolysis of a $20 \mathrm{mM}$ titanium diisopropoxide bis(acetylacetonate) solution (Aldrich) at $450{ }^{\circ} \mathrm{C}$. A mesoporous $\mathrm{TiO}_{2}$ layer was deposited from a commercially available paste (18-nrt, dyesol) diluted 2:13 wt. with ethanol before spin coating at $2000 \mathrm{rpm}$ for 30 seconds and sintering at $450^{\circ} \mathrm{C}$. Next a perovskite precursor solution was made using the same method as the film preparation described. The perovskite precursor solution was coated using a spin coating procedure using two speeds where toluene was dripped onto the surface during the second step and then dried at $100^{\circ} \mathrm{C}$ post deposition. In instances spiro-OMeTAD was used as a HTM, a solution of $\quad 8 \% \quad$ wt. 2,2',7,7'-tetrakis[N,N-di(4methoxyphenyl)amino]-9,9'-spirobifluorene (spiroOMeTAD, Borun Chemical) in chlorobenzene was next spin-coated onto the perovskite films. The spiro-OMeTAD solution contained additives including $19 \mathrm{mM}$ bis(trifluoromethane)sulfonimide lithium salt (Li-TFSI), 7 $\mathrm{mM}$ 4-tert-butylpyridine (tBP). Oxidising dopant $\mathrm{V}_{2} \mathrm{O}_{5}$ (99.99\%, Aldrich) was also added to the spiro-OMeTAD solution in the quantity of $2.5 \%$ wt with respect to the spiroOMeTAD powder. In instances P3HT was used as a HTM, a $12 \mathrm{mg} \mathrm{ml}^{-1}$ solution of high molecular weight poly(3hexylthiophene) (P3HT) (Mw 135k, PDI 1.5, RR 99\%) in chlorobenzene was spin-coated onto perovskite films at $2000 \mathrm{rpm}$ for $30 \mathrm{s.}^{23}$ Finally a $50 \mathrm{~nm}$ Au contact was evaporated onto the cell under vacuum leaving an active area of $0.15 \mathrm{~cm}^{2}$

\subsection{Device environmental stability characterisation}

Initial current-voltage characteristics were measured using a Xenon lamp at AM1.5 solar illumination (Oriel Instruments) calibrated to a silicon reference cell with a Keithley 2400 source meter. Cyclic scans were performed from $0 \mathrm{~V}$ to $1.5 \mathrm{~V}$ forward bias and back to $0.5 \mathrm{~V}$ reverse bias at a rate of $0.125 \mathrm{~V} \mathrm{~s}^{-1}$ shown in Fig S2. Cells were unmasked during measurements, using the area created by the overlap of the metallic contact and the FTO substrate as the defined active area of $0.15 \mathrm{~cm}^{2}$. During stability measurements the current-voltage scan was performed from $1.5 \mathrm{~V}$ forward bias to $-0.5 \mathrm{~V}$ reverse bias and held at open circuit conditions between measurements. Atmospheric conditions of device stability performance was monitored using the environmentally controlled glovebox described in the thin film characterisation.

\subsection{X-ray Diffraction Measurements}

X-ray diffraction (XRD) measurements on thin film samples with glass substrates were performed using a Bruker D8 Discover X-ray diffractometer equipped with $\mathrm{Ni}$ filtered $\mathrm{Cu}$ Ka radiation $(\lambda=1.5406 \AA$ ) operating at $40 \mathrm{kV}$ and $40 \mathrm{~mA}$. XRD patterns were acquired in BraggBrentano geometry with a standard $2 \theta$ step size of 0.01671 degree from 10 degree to 40 degree at 26 s degree $^{-1}$.

\subsection{Transient Absorption Spectroscopy Measurements}

Sub-microsecond timescales transient absorption spectroscopy (us-TAS) decays were acquired on a custom-built system. Samples were excited at $420 \mathrm{~nm}$ (40 $\mathrm{uJ} \mathrm{cm}^{-2}$ ) by an Opolette 355 laser (OPOTEK), white probe 
light generated by a tungsten halogen lamp and detected by a silicon photodiode detector. A probe wavelength of $530 \mathrm{~nm}$ was selected by a monochromator and long pass optical filters used to limit light exposure to the sample and reduce the effect of laser scatter. Samples were measured in $\mathrm{N}_{2}$ or dry air atmosphere, as required.

\subsection{Superoxide monitoring}

A stock solution $(31.7 \mu \mathrm{m})$ of the hydroethidine $(\mathrm{HE})$ probe was prepared by dissolving $10 \mathrm{mg} \mathrm{HE}$ in $10 \mathrm{~mL}$ of dry toluene; sonication was used to facilitate miscibility. Films were then added to $10 \mathrm{~mL}$ of $0.317 \mu \mathrm{m}$ solution created from the stock solution. Photoluminescence spectra were recorded using an excitation wavelength of $520 \mathrm{~nm}$ and a slit width of $10 \mathrm{~nm}$ on a Horiba Jobin-Yvon Fluorolog-3 spectrofluorometer. In the experiments with oxygen involved, dry oxygen was bubbled through the toluene. Spectral mismatch correction for the varying ratio of halide are calculated with equ (2):

$$
I_{F}(t) / I_{F}\left(t_{0}\right)(\text { corected for absorption })=1+\frac{I_{F}(t)-I_{F}\left(t_{0}\right)}{\beta \times I_{F}\left(t_{0}\right)}
$$

where $I_{F}(t)$ is the fluorescence intensity average from $605-615 \mathrm{~nm}$ at time $t, I_{F}\left(t_{0}\right)$ is at $t=0 \min$ and $\beta$ is the spectral mismatch factor relative to $\mathrm{CH}_{3} \mathrm{NH}_{3} \mathrm{Pbl}$, given in Table S4.

\subsection{NMR measurements}

Potassium superoxide and methylammonium bromide were dissolved in a 1:1 molar ratio in dry ethanol. The reaction was monitored by $1 \mathrm{H}$ NMR using a $400 \mathrm{MHz}$ Bruker spectrometer. Deuterated acetone was added to the solution prior to the NMR spectroscopy for calibration of the spectrum.

\section{Results and Discussion}

\subsection{Thin film stability characterisation}

To assess the stability of mixed halide perovskites, the material properties of neat films deposited on glass (see Methods) were first investigated, expanding on recent results reported on thin film samples. ${ }^{24} \mathrm{~A}$ range of six concentrations of $\mathrm{CH}_{3} \mathrm{NH}_{3} \mathrm{~Pb}\left(\mathrm{I}_{(1-x)} \mathrm{Br}_{\mathrm{x}}\right)_{3}$, from $\mathrm{x}=0$ - 1, were exposed to controlled environmental conditions to analyse the effect of mixed halide films to high humidity conditions and to light and dry air conditions. To investigate the hydration, the films were held at a controlled $\mathrm{RH}$ within a nitrogen atmosphere in low light and the optical changes were monitored with a camera. An inert atmosphere and low light levels ensured the degradation was isolated to effects from humidity only. This degradation mechanism has been shown to cause the dark perovskite phase to form a visibly transparent mono-hydrated perovskite phase and therefore it is possible to monitor this degradation process via optical changes. ${ }^{16}$ The humidity was incrementally adjusted from $80 \%$ to $97 \%$ over a series of days. Example camera images from 13-18 hr in Fig 1a are shown in Supporting Information (Table S1); from these data the time course of optical absorption degradation were determined for each sample (see Methods for details), as shown in Fig 1a. It is apparent from this figure that films with increased bromide ratio have higher tolerance to hydration degradation and are stable at higher levels of $\mathrm{RH}$. Rapid degradation of $\mathrm{CH}_{3} \mathrm{NH}_{3} \mathrm{Pbl}_{3}$ to the mono-hydrate phase is shown at $85 \% \mathrm{RH}$ whereas $\mathrm{CH}_{3} \mathrm{NH}_{3} \mathrm{~Pb}\left(\mathrm{I}_{0.5} \mathrm{Br} 0.5\right)_{3}$ does not show significant changes below $95 \% \mathrm{RH}$. Interestingly, for all halide ratios full reversibility of the films from the mon-hydrate phase to the perovskite phase was observed if films were kept in a nitrogen atmosphere and below the saturation point; the dehydrate phase previously report in experiments in humid air was not observed. ${ }^{16}$

We now turn to investigating the stability of the mixed halide perovskite photoactive films in the presence of oxygen and light; films were exposed to conditions of 1 sun equivalent visible LED intensity and dry air. On exposure to these conditions, an optical change in the methyl ammonium lead iodide perovskite is observed with the absorption onset shifting from $780 \mathrm{~nm}$ to lead iodide at $520 \mathrm{~nm} .{ }^{21}$ Therefore it is possible to monitor the degradation via a change in the optical absorption of the $\mathrm{CH}_{3} \mathrm{NH}_{3} \mathrm{~Pb}\left(\mathrm{I}_{1-\mathrm{x}} \mathrm{Br}_{\mathrm{x}}\right)_{3}$ pristine films in Fig $\mathrm{S} 1$. Optical absorption degradation in light and dry air for our series of mixed halide perovskites is shown in Fig 1b. Control data in light and nitrogen showed no significant degradation, consistent with previous studies. ${ }^{22}$ The data in Fig $1 \mathrm{~b}$ shows exposure to light and oxygen causes films containing iodide initially start to degrade to lead iodide at approximately equal rates for all concentrations of iodide; in contrast $\mathrm{CH}_{3} \mathrm{NH}_{3} \mathrm{PbBr}_{3}$ films show remarkable stability under these conditions. After $130 \mathrm{hr}$ exposure to light and dry air, only a very small change in optical characteristics are observed for the $\mathrm{CH}_{3} \mathrm{NH}_{3} \mathrm{PbBr}_{3}$ film. A time to $50 \%$ optical change for the $\mathrm{CH}_{3} \mathrm{NH}_{3} \mathrm{PbBr}_{3}$ is extrapolated to over $5500 \mathrm{hr}$ compared to $9.8 \mathrm{hr}$ for $\mathrm{CH}_{3} \mathrm{NH}_{3} \mathrm{Pbl}_{3}$, more than a two orders of magnitude improvement in stability. For the mixed halide films, bromide can be seen to reduce the overall time for degradation, whereas the $x=0$ film fully 
(a)

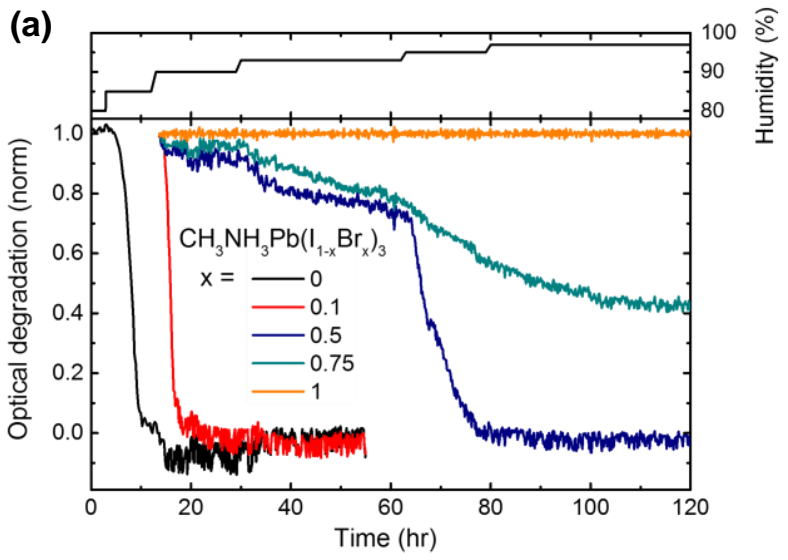

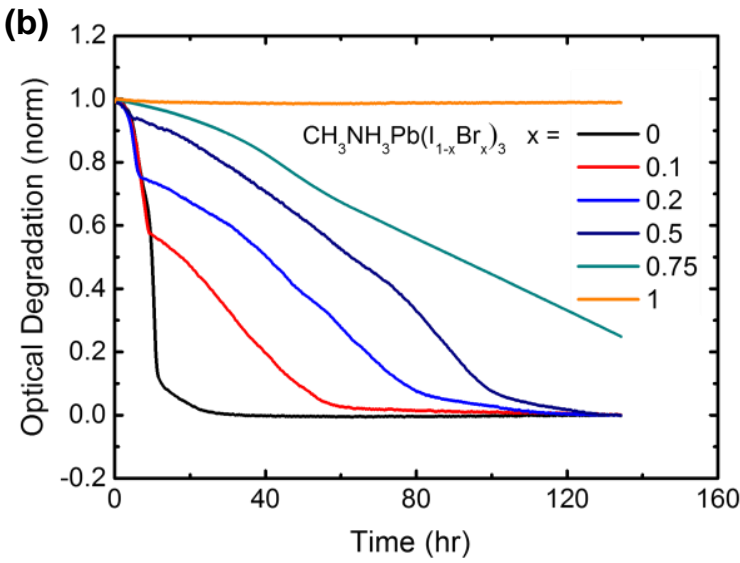

Figure 1. (a) Optical analysis of $\mathrm{CH}_{3} \mathrm{NH}_{3} \mathrm{~Pb}\left(l_{(1-x)} \mathrm{Br}_{x}\right)_{3}(\mathrm{x}=0,0.1,0.5,0.75,1)$ films exposed to humid conditions in a nitrogen atmosphere. The humidity was incrementally increase over the course of $120 \mathrm{hr}$ from $80 \%$ to $97 \%$. Increasing bromide ratio improved stability but only $x=1$ did not degrade. (b) Optical analysis of $\left.\mathrm{CH}_{3} \mathrm{NH}_{3} \mathrm{~Pb}\left(\mathrm{l}_{(1-x)}\right) \mathrm{Br}_{\mathrm{x}}\right)_{3}(\mathrm{x}=0,0.1,0.2,0.5,0.75,1)$ films exposed to 1 sun eqv LED light in dry air. For $x<1$ films start to degrade at the same time but increasing bromide ratio slows the rate of degradation and only $\mathrm{x}=1$ does not degrade.

degrades after $10 \mathrm{hr}$, the $\mathrm{x}=0.5$ film took over $100 \mathrm{hr}$ to fully degrade. In the optical property investigations of $\mathrm{x}=0.1,0.2$, and 0.5 two clear stages of degradation are seen, with a rapid decrease within the first $10 \mathrm{hr}$ followed by a slower degradation phase. Increased bromine content reduces the proportion of the rapid decay phase but not its kinetics. This fast degradation phase can be assigned most obviously to degradation of iodide clusters of the mixed structure, with the rate of degradation of these iodide regions not being protected by the presence of bromine in the mixed film. Previous studies in literature demonstrated the importance of iodide in perovskite stability, which is likely the reason mixed halide degradation is observed but $\mathrm{X}=1$ perovskite shows impressive stability. ${ }^{25}$ In mixed halide films up to 0.75 bromide, the bromide does not prolong the initiation of degradation in light and oxygen but rather only extends the time of complete degradation. This contrasts to the effect of bromide substitution on hydration induced degradation, where the onset of degradation is seen to shift to higher levels of $\mathrm{RH}$ with increased bromide ratio. In summary, we observe that under oxygen and light stress, $\mathrm{CH}_{3} \mathrm{NH}_{3} \mathrm{PbBr}_{3}$ films are over two orders of magnitude more stable than $\mathrm{CH}_{3} \mathrm{NH}_{3} \mathrm{Pbl}_{3}$, but that in mixed halide systems, the presence of $\geq 0.75$ iodide results in a rapid initial optical absorption degradation.

It is apparent from Fig $1 \mathrm{~b}$ that even for the least stable $\mathrm{CH}_{3} \mathrm{NH}_{3} \mathrm{Pbl}_{3}$ films, there is a time delay of $\sim 4$ hours from initiating the light soaking before the onset of significant absorption degradation. In order to identify if this time delay could be associated with kinetics of oxygen diffusion into the films, we investigated the effect of dry air exposure time prior to light turn on, varying the air exposure time from 0.5 to $48 \mathrm{hr}$ before exposure to light soaking. The resulting optical degradation results are shown in Fig S2a, and indicate that all films degraded at the same rate independent of the air soaking time. This suggests that prior oxygen diffusion into the film does not limit the degradation process observed in these studies. Rather it appears more likely that this time delay in the onset of light and oxygen induced degradation is due to degradation products resulting in an autocatalytic reaction sequence, as discussed previously.

Current high performing perovskite devices contain mixed organic cations in the perovskite structure, typically both formamidinium and methyl ammonium cations. ${ }^{1,7,26}$ To address the effect of such organic cation substitution, optical degradation data was also collected for a thin film of $\left[\mathrm{CH}_{2}\left(\mathrm{NH}_{2}\right)_{2}\right]_{0.85}\left[\mathrm{CH}_{3} \mathrm{NH}_{3}\right]_{0.15} \mathrm{~Pb}\left(\mathrm{l}_{0.85} \mathrm{Br} \mathrm{Br}_{15}\right)_{3}$ in dry air and 1 sun light, as shown in Fig S2b. These data show similar overall degradation kinetics to the equivalent $\mathrm{CH}_{3} \mathrm{NH}_{3} \mathrm{~Pb}\left(\mathrm{I}_{(1-x)} \mathrm{Br}_{\mathrm{x}}\right)_{3}$ films, apart from a longer time delay before the onset of degradation, suggesting that the oxygen and light degradation mechanism may also limit stability of mixed organic cation perovskite materials.

\subsection{Device stability}

To investigate how the degradation of the perovskite photoactive layer affects photovoltaic performance of complete PSC, complete devices were fabricated and analysed. Full details of device fabrication are given in the Methods section. In short, mesoporus titania perovskite devices with $\mathrm{P} 3 \mathrm{HT}$ as a hole transporting material (HTM) were fabricated in a $\mathrm{FTO} / \mathrm{TiO} 2-\mathrm{bl} / \mathrm{TiO}_{2}-\mathrm{mp} / \mathrm{CH}_{3} \mathrm{NH}_{3} \mathrm{~Pb}\left(\mathrm{I}_{1}\right.$ $\left.{ }_{x} \mathrm{Br}_{\mathrm{x}}\right)_{3} / \mathrm{P} 3 \mathrm{HT} / \mathrm{Au}$ architecture where $\mathrm{TiO}_{2}-\mathrm{bl}$ is a titanium dioxide compact layer and $\mathrm{TiO}_{2}-\mathrm{mp}$ is a mesoporous titanium dioxide layer. The P3HT used was undoped to mitigate additional instabilities resulting from dopants. Current voltage characteristics of devices in Fig S3 shows, 
(a)

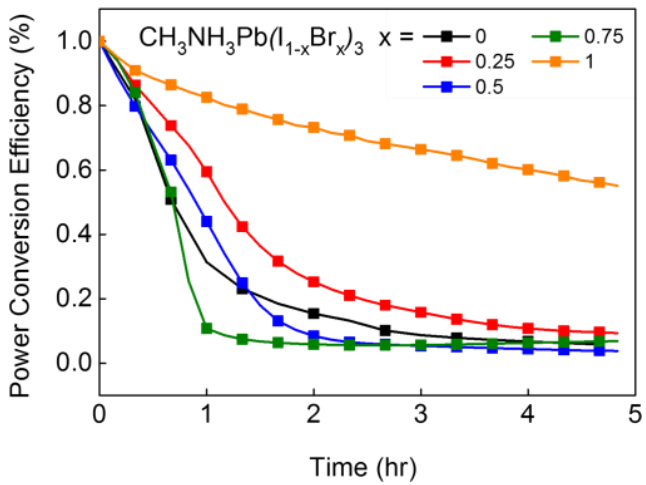

(b)

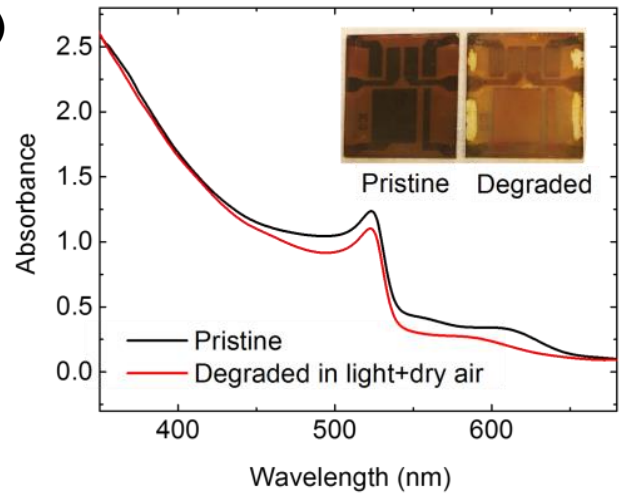

Figure 2. (a) Power conversion data of $\left.\mathrm{CH}_{3} \mathrm{NH}_{3} \mathrm{~Pb}\left(\mathrm{I}_{1}-\mathrm{x}\right) \mathrm{Br}_{\mathrm{x}}\right)_{3}(\mathrm{x}=0,0.1,0.5,0.75,1)$ solar cell devices exposed to 1 sun eqv. LED light and dry air of device structure $\mathrm{FTO} / \mathrm{TiO} 2-\mathrm{bl} / \mathrm{TiO}_{2}-\mathrm{mp} / \mathrm{CH}_{3} \mathrm{NH}_{3} \mathrm{~Pb}\left(\mathrm{I}_{1-\mathrm{B}} \mathrm{Br} \times\right)_{3} / \mathrm{P} 3 \mathrm{HTT} / \mathrm{Au}$. Devices were held at open circuit between measurements. Rapid device degradation after $2 \mathrm{hr}$ is shown for devices with $\mathrm{x}<1$ but $\mathrm{x}=1$ shows stability up $5 \mathrm{hr}$. (b) Absorbance data of a $\mathrm{CH}_{3} \mathrm{NH}_{3} \mathrm{PbBr}_{3}$ device before and after degradation in dry air and 1 sun LED illumination. A point next to the evaporated top contact was measured to allow for transmission measurements. The difference of the fresh and pristine device is shown as the photobleaching of the $\mathrm{P} 3 \mathrm{HT}$ absorption at $520 \mathrm{~nm}$ where $\mathrm{CH}_{3} \mathrm{NH}_{3} \mathrm{PbBr}_{3}$ does not absorb.

as expected, a drop in short circuit current and increase in open circuit voltage from $x=0$ to $x=1$ due the change in band gap. These devices were then exposed to light and dry air in the environmental chamber and their photovoltaic performance monitored as a function of time under the same AM1.5 equivalent LED light exposure as that employed for the optical degradation data. The solar cell device stability data are shown in Fig $2 a$. This figure shows that for $\mathrm{x}<1$ the degradation of PCE is approximately the same rate with a $50 \%$ drop in PCE after 1-1.5 hr. In contrast, the $\mathrm{x}=1$ device, $\mathrm{CH}_{3} \mathrm{NH}_{3} \mathrm{PbBr}_{3}$, shows relatively good stability, with a fivefold increase in device lifetime relative to the iodine containing devices. In all cases, the loss of PCE was primarily caused by a loss of photocurrent with a $50 \%$ drop in performance taking over three times longer than a $x<1$ device. We note that, as for the film optical degradation data, the $x=0.75$ device is substantially less stable than the $\mathrm{x}=1$ all bromine device; these two devices differ in optical bandgap by only $50 \mathrm{~nm}$ (Fig S1), clearly indicating that the increase in stability for the all bromine device does not primarily derive from a difference in light absorption. It is also apparent that the device PCE degradation data shown in Fig 2a exhibit much faster degradation than the film optical degradation data shown in Fig 1b. This indicates that even small amounts of degradation in the perovskite photoactive layer can dramatically reduce the performance of a device. This conclusion is also supported by our observation that all iodine containing devices $(x<1)$ show similarly rapid $P C E$ degradation, as our optical degradation data shows an initial fast optical degradation decay phase for iodide containing films, independent of bromine content. We conclude that $\mathrm{CH}_{3} \mathrm{NH}_{3} \mathrm{PbBr}_{3}$ solar cells are significantly more resistant to light and oxygen induced degradation than $\mathrm{CH}_{3} \mathrm{NH}_{3} \mathrm{Pbl}_{3}$ solar cells, however inclusion of bromide in a mixed halide photovoltaic device does not increase the stability under this stress condition.

The $\mathrm{CH}_{3} \mathrm{NH}_{3} \mathrm{PbBr}_{3}$ solar cell exhibits a fivefold increase in device efficiency lifetime under light and oxygen relative to $\mathrm{CH}_{3} \mathrm{NH}_{3} \mathrm{Pbl}_{3}$ devices, substantially less than the $\sim 500$ fold increase in optical degradation time observed in our film data. Previous studies in literature have shown reactions between device interlayers can limit stability, such as the gold top electrode diffusing to the perovskite active layer ${ }^{27}$. Therefore the instability of $\mathrm{CH}_{3} \mathrm{NH}_{3} \mathrm{PbBr}_{3}$ devices may be due an interaction between the perovskite layer and gold. However, at the operating condition used here, $35^{\circ} \mathrm{C}$, insignificant metallic diffusion occurs over the time scales measured ${ }^{27}$. Upon further investigation it was found that the organic P3HT HTM layer in these devices exhibited significant photo-bleaching upon this exposure to light and oxygen. This is apparent as a loss of absorption between 450 and $650 \mathrm{~nm}$, a wavelength range corresponding to $\mathrm{P} 3 \mathrm{HT}$ absorption and distinct from $\mathrm{CH}_{3} \mathrm{NH}_{3} \mathrm{PbBr}_{3}$ absorption (see Fig $2 \mathrm{~b}$, onset at $~ 525 \mathrm{~nm}$ ). We therefore ascribe the decrease in performance of $\mathrm{CH}_{3} \mathrm{NH}_{3} \mathrm{PbBr}_{3}$ devices primarily to degradation of the organic P3HT HTM layer, and subsequent loss of charge transport properties from the perovskite to the electrode, indicating that the perovskite layer is not limiting stability in this instance. We note replacement of $\mathrm{P} 3 \mathrm{HT}$ with doped spiro-OMeTAD as the HTM resulted in rapid device degradation independent of bromine content, as shown in Fig S4, suggesting that this HTM layer is particularly sensitive to degradation under light and oxygen. 

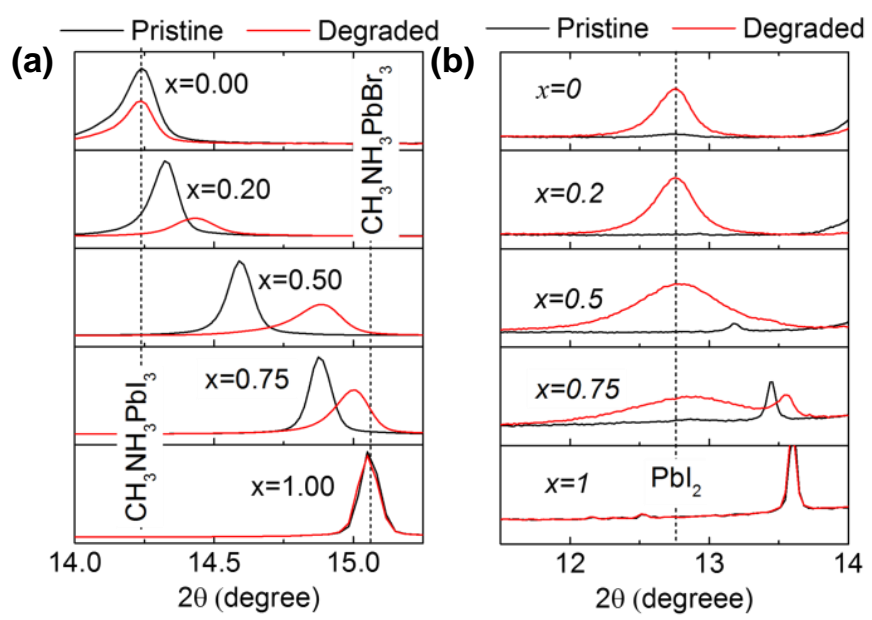

Figure 3. XRD analysis of $\mathrm{CH}_{3} \mathrm{NH}_{3} \mathrm{~Pb}\left(\mathrm{l}_{(1-x)} \mathrm{Br}_{\mathrm{x}}\right)_{3}(\mathrm{x}=0.00$, $0.20,0.50,0.75,1.00)$ films before and after exposed to light and dry air for $6 \mathrm{hr}$, (a) showing the region of the tetragonal (220) and cubic (200) peaks. Degraded films show a shift to the bromide, cubic structure indicating a loss of the iodide perovskite phase. At $x=1$, the peak is shown to be very stable. (b) XRD analysis focusing on the lead iodide peak showing the formation of lead iodide in all halide ratios, but not lead bromide. At lower iodide ratios, the FWHM greatly increases due to the formation being more amorphous.

\section{Probing the degradation mechanism}

To understand in more detail, the mechanism(s) causing the oxygen and light induced degradation in film absorbance and device PCE, further characterisation measurements were performed on mixed halide perovskite films. Fig 3a shows XRD spectra analysis the crystal lattice phase before and after $6 \mathrm{hr}$ light and oxygen exposure. These data indicate a continuous shift from the tetragonal $\mathrm{CH}_{3} \mathrm{NH}_{3} \mathrm{Pbl}_{3}$ peak at $14.2^{\circ}$ to the cubic $\mathrm{CH}_{3} \mathrm{NH}_{3} \mathrm{PbBr}_{3}$ peak at $15.05^{\circ}$ with increasing bromide concentrations, indicating that these films form an intermixed structure on the length scale of X-Ray diffraction (75-100 nm). Following exposure to light and dry air for six hours the crystal lattice peak of the mixed halide films $(x=0.25,0.5$ and 0.75 ) can be seen to shift to towards higher angles, indicating a reduction in iodide content in the perovskite regions of the film. Furthermore, the XRD peak of lead iodide can be seen to form in Fig $3 b$ for all iodide containing perovskites but no lead bromide peak is observed. Note the peak at $13.6^{\circ}$ is the perovskite crystal, hence the shift seen in the $x=0.75$ after degradation. At lower iodide concentrations a larger full width at half maximum (FWHM) of the lead iodide peak is observed indicating a more amorphous structure. These data are indicative that for the mixed halide films, light and oxygen degradation results in a reduction of iodide content in the perovskite phase of the film (and therefore increased bromide content of this
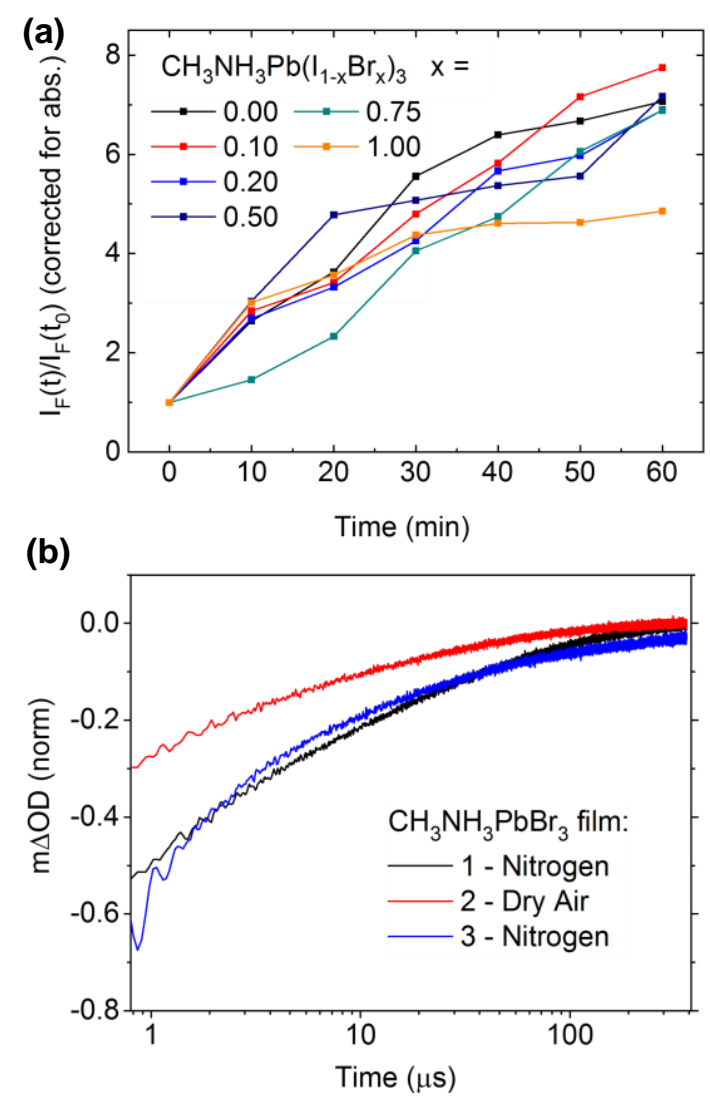

Figure 4. (a) Fluorescence intensity of superoxide probe at $610 \mathrm{~nm}$, with excitation at $520 \mathrm{~nm}$, where $I_{F}(t)$ is the florescence intensity at time $t$ and $I_{F}(0)$ is the fluorescence of the probe at $\mathrm{t}=0 \mathrm{~min}$. A spectral mismatch correction between the thin film absorption and tungsten-halogen light source gives the superoxide generation all halide ratios relative to $\mathrm{CH}_{3} \mathrm{NH}_{3} \mathrm{Pbl}_{3}$ absorption. Absorption correction calculations can be seen in Methods. (b) Transient absorption measurements of $\mathrm{CH}_{3} \mathrm{NH}_{3} \mathrm{PbBr}_{3}$ thin films exciting at $400 \mathrm{~nm}$ and probing the photobleaching signal at $520 \mathrm{~nm}$. On exposure to air, quenching of the charge carrier population can be seen by a reduction (1-2) in the photobleaching signal, and returns with re-exposure to nitrogen (2-3).

phase), and the concomitant formation of lead iodide. We note this observation of a mixed iodide/bromide phase on the 75-100 nm lengthscale of XRD diffraction contrasts with photoluminescence data which indicates that the mixed halide films exhibit an emission maxima close to the lower energy $\mathrm{CH}_{3} \mathrm{NH}_{3} \mathrm{Pbl}_{3}$ emission peak independent of bromide content (Fig S5, as previously reported, ${ }^{28}$ ). This emission data indicates the presence of small $\mathrm{CH}_{3} \mathrm{NH}_{3} \mathrm{Pbl}_{3}$ clusters in all mixed halide films, with photoluminescence from the mixed films primarily deriving from these clusters.

Previously we have shown the degradation mechanism for $\mathrm{CH}_{3} \mathrm{NH}_{3} \mathrm{Pbl}_{3}$ films and devices under light and oxygen stress to be part of a reaction series involving the transfer 


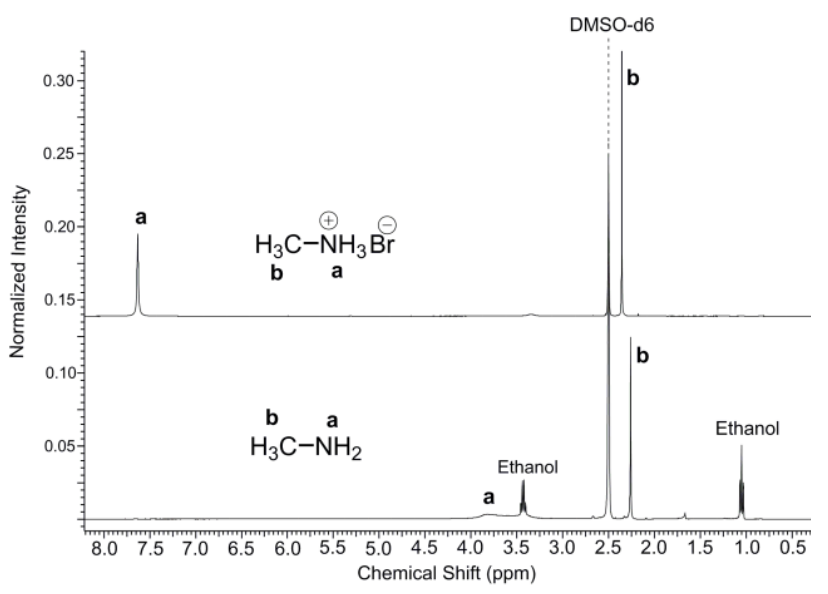

Figure 5: NMR spectra of a reference methyl ammonium bromide sample before (top) and after (after) the addition of potassium superoxide showing the reactivity of $\mathrm{CH}_{3} \mathrm{NH}_{3} \mathrm{Br}$ to superoxide.

of photogenerated $\mathrm{CH}_{3} \mathrm{NH}_{3} \mathrm{Pbl}_{3}$ electrons to molecular oxygen, resulting in the formation of superoxide $\left(\mathrm{O}_{2}{ }^{-}\right)$. Therefore, to assess the role of superoxide in the degradation of mixed halide perovskite films under exposure to light and oxygen, $\mathrm{CH}_{3} \mathrm{NH}_{3} \mathrm{~Pb}\left(\mathrm{I}_{1-x} \mathrm{Br}\right)_{3}$ films were monitored using a previously reported method. ${ }^{21}$ Superoxide generation was monitored over a $60 \mathrm{~min}$ period and it is shown in Fig $4 a$ that all films form superoxide. When normalised for differences in film light absorption it is apparent that the rate of superoxide generation is independent of the iodide / bromide content of the film. This indicates that the increased stability of the $\mathrm{CH}_{3} \mathrm{NH}_{3} \mathrm{PbBr}_{3}$ film does not result from an inability to generate superoxide. Supporting this conclusion, transient absorption spectroscopy was employed to monitor the absorbance of long lived $\mathrm{CH}_{3} \mathrm{NH}_{3} \mathrm{PbBr}_{3}$ electrons and holes following pulsed laser excitation, monitoring their ground state bleach signal at $530 \mathrm{~nm}$ (following previous literature reports). As shown in Fig 4b, exposure to oxygen resulted in significant reversible quenching (Fig S6) in the amplitude of this bleach signal, indicating that oxygen can indeed react with photogenerated $\mathrm{CH}_{3} \mathrm{NH}_{3} \mathrm{PbBr}_{3}$ charge carriers, again indicative with $\mathrm{O}_{2}^{-}$formation and indicating that $\mathrm{CH}_{3} \mathrm{NH}_{3} \mathrm{PbBr}_{3}$ 's excellent stability does not derive from an inability to form superoxide.

Superoxide can act as a proton scavenging free radical which has been suggested to break down the $\mathrm{CH}_{3} \mathrm{NH}_{3} \mathrm{Pbl}{ }_{3}$ perovskite structure via a deprotonation reaction of the methylammonium group. ${ }^{21}$ The Pauling electronegativity of bromine is 0.03 higher compared to iodine and therefore will increase the stabilisation to the methyl ammonium group due to the increased intermolecular interaction. To test if exchanging iodide for bromide leads to a change in the reactivity between methyl ammonium cations and the superoxide species, we undertook a solution study of the reaction of $\mathrm{CH}_{3} \mathrm{NH}_{3} \mathrm{Br}$ and $\mathrm{CH}_{3} \mathrm{NH}_{3} \mathrm{l}$ with potassium superoxide, following previous literature procedures. ${ }^{21}$ Proton NMR spectra of the reaction products in Fig 5 show the signal for the $\mathrm{NH}_{3}{ }^{+}$and the methyl group protons shift up-field upon addition of potassium superoxide, which is consistent with the deprotonation of the ammonium group to form methylamine $\left(\mathrm{CH}_{3} \mathrm{NH}_{2}\right)$ suggesting there is no difference in reactivity of the cation owed to the changing anion species. It is suggested that the reason superoxide does not degrade the $\mathrm{CH}_{3} \mathrm{NH}_{3} \mathrm{PbBr}_{3}$ structure is due to the increased thermodynamic stability of the crystal structure, compared to $\mathrm{CH}_{3} \mathrm{NH}_{3} \mathrm{Pbl}_{3}$. A report of first-principle calculations has shown that $\mathrm{CH}_{3} \mathrm{NH}_{3} \mathrm{Pbl}_{3}$ is thermodynamically unstable at room temperature with respect to a phase segregation to $\mathrm{CH}_{3} \mathrm{NH}_{3} \mathrm{I}_{3}$ and $\mathrm{Pbl}_{2}$ with a negative energy cost of -0.060 to $-0.063 \mathrm{eV} / \mathrm{f}$.u. In contrast, $\mathrm{CH}_{3} \mathrm{NH}_{3} \mathrm{PbBr}_{3}$ is thermodynamically stable compared to the corresponding phase segregation to $\mathrm{CH}_{3} \mathrm{NH}_{3} \mathrm{Br}_{3}$ and $\mathrm{PbBr}_{2}$ with a positive energy cost of 0.077 to $0.065 \mathrm{eV} / \mathrm{f} . \mathrm{u}^{29}$ This result indicates that the crystal structure of $\mathrm{CH}_{3} \mathrm{NH}_{3} \mathrm{PbBr}_{3}$ is thermodynamically more stable than $\mathrm{CH}_{3} \mathrm{NH}_{3} \mathrm{Pbl}_{3}$, which appears to be the most likely reason superoxide degrades the $\mathrm{CH}_{3} \mathrm{NH}_{3} \mathrm{PbBr}_{3}$ perovskite structure at a dramatically slower rate, and the reason why in the mixed halide films, the iodide component of the film is preferentially degraded to $\mathrm{Pbl}_{2}$.

\section{Conclusions}

In summary, this work indicates the major instability of $\mathrm{CH}_{3} \mathrm{NH}_{3} \mathrm{Pbl}_{3}$ devices to light and oxygen is also seen in mixed iodide/bromide $\mathrm{CH}_{3} \mathrm{NH}_{3} \mathrm{~Pb}\left(\mathrm{I}_{1-\mathrm{x}} \mathrm{Br}_{\mathrm{x}}\right)_{3}$ devices; however, in $\mathrm{CH}_{3} \mathrm{NH}_{3} \mathrm{PbBr}_{3}$ devices both films and devices show significantly improved stability in these conditions. XRD measurements show the iodide perovskite degrading separately to the bromide phase in mixed films. The improved stability of $\mathrm{CH}_{3} \mathrm{NH}_{3} \mathrm{PbBr}_{3}$ films and devices is shown not to derive from lower yields of superoxide formation, but rather are attributed to the increased thermodynamic stability of the $\mathrm{CH}_{3} \mathrm{NH}_{3} \mathrm{PbBr}_{3}$ crystal structure. Promisingly, the stability of bromide perovskite device under light and oxygen stress was found to be limited by the organic HTM interlayer and not by the perovskite photoactive layer. With the development of stable interlayers unsealed $\mathrm{CH}_{3} \mathrm{NH}_{3} \mathrm{PbBr}_{3}$ devices can be produced with excellent stability in ambient air under irradiation, with potential application in high voltage or 4terminal tandem solar cells.

\section{Notes}

The authors declare no competing financial interest. Data underlying this article will be made available on the Zenodo repository at 10.5281 /zenodo.439257. 


\section{Acknowledgments}

Financial support from the Engineering and Physical Sciences Research Council (EPSRC, EP/M023532/1, $E P / K 010298 / 1$ and EP/K030671/1). Solvay SA and the Welsh Assembly Government Sêr Cymru programme are gratefully acknowledged.

\section{References}

1. Li X, Bi D, Yi C, et al. A vacuum flash-assisted solution process for high-efficiency large-area perovskite solar cells. Science (80-. ). 2016;353(6294):58-62. doi:10.1126/science.aaf8060.

2. Kojima A, Teshima K, Shirai Y, Miyasaka T. Organometal Halide Perovskites as Visible-Light Sensitizers for Photovoltaic Cells. J. Am. Chem. Soc. 2009;131(17):6050-6051. doi:10.1021/ja809598r.

3. Lee MM, Teuscher J, Miyasaka T, Murakami TN, Snaith HJ. Efficient Hybrid Solar Cells Based on Meso-Superstructured Organometal Halide Perovskites. Science (80-. ). 2012;338(6107):643-647. doi:10.1126/science.1228604.

4. Kim H-S, Lee $\mathrm{C}-\mathrm{R}$, Im J-H, et al. Lead lodide Perovskite Sensitized All-Solid-State Submicron Thin Film Mesoscopic Solar Cell with Efficiency Exceeding 9\%. Sci. Rep. 2012;2:1-7. doi:10.1038/srep00591.

5. Burschka J, Pellet N, Moon S-J, et al. Sequential deposition as a route to high-performance perovskitesensitized solar cells. Nature 2013;499(7458):316319. doi:10.1038/nature12340.

6. Jeon NJ, Noh JH, Kim YC, Yang WS, Ryu S, Seok S II. Solvent engineering for high-performance inorganic-organic hybrid perovskite solar cells. Nat. Mater. 2014;13(9):897-903. doi:10.1038/nmat4014.

7. Saliba M, Matsui T, Seo J-Y, et al. Cesium-containing triple cation perovskite solar cells: improved stability, reproducibility and high efficiency. Energy Environ. Sci. 2016;9(6):1989-1997. doi:10.1039/C5EE03874J.

8. Chen W, Wu Y, Yue $Y$, et al. Efficient and stable large-area perovskite solar cells with inorganic charge extraction layers. Science (80-. ).

2015;350(6263):944-948.

doi:10.1126/science.aad1015.

9. Li X, Tschumi M, Han H, et al. Outdoor Performance and Stability under Elevated Temperatures and LongTerm Light Soaking of Triple-Layer Mesoporous Perovskite Photovoltaics. Energy Technol. 2015;3(6):551-555. doi:10.1002/ente.201500045.

10. Dyesol Ltd. Dyesol Proves Perovskiite Solar Cell Stability. Press release 2015;09 August(August):1-2.

11. Li X, Ibrahim Dar M, Yi C, et al. Improved performance and stability of perovskite solar cells by crystal crosslinking with alkylphosphonic acid $\omega$-ammonium chlorides. Nat. Chem. 2015;7(9):703-711. doi:10.1038/nchem.2324.
12. Yang S, Wang $Y$, Liu $P$, Cheng $Y-B$, Zhao HJ, Yang HG. Functionalization of perovskite thin films with moisture-tolerant molecules. Nat. Energy 2016;1(2):15016. doi:10.1038/nenergy.2015.16.

13. Ito S, Tanaka S, Vahlman H, Nishino H, Manabe $K$, Lund $\mathrm{P}$. Carbon-double-bond-free printed solar cells from $\mathrm{TiO}_{2} / \mathrm{CH}_{3} \mathrm{NH}_{3} \mathrm{Pbl}_{3} / \mathrm{CuSCN} / \mathrm{Au}$ : structural control and photoaging effects. Chemphyschem 2014;15(6):1194-200. doi:10.1002/cphc.201301047.

14. Yu D, Yang Y-Q, Chen Z, Tao Y, Liu Y-F. Recent progress on thin-film encapsulation technologies for organic electronic devices. Opt. Commun. 2016;362:43-49. doi:10.1016/j.optcom.2015.08.021.

15. Leijtens T, Eperon GE, Noel NK, Habisreutinger SN, Petrozza A, Snaith HJ. Stability of Metal Halide Perovskite Solar Cells. Adv. Energy Mater. 2015;5(20):1500963. doi:10.1002/aenm.201500963.

16. Leguy AMA, Hu Y, Campoy-Quiles M, et al. Reversible Hydration of $\mathrm{CH} 3 \mathrm{NH} 3 \mathrm{Pbl} 3$ in Films, Single Crystals, and Solar Cells. Chem. Mater. 2015;27(9):3397-3407. doi:10.1021/acs.chemmater.5b00660.

17. Smith IC, Hoke ET, Solis-Ibarra D, McGehee MD, Karunadasa HI. A Layered Hybrid Perovskite SolarCell Absorber with Enhanced Moisture Stability. Angew. Chemie Int. Ed. 2014;53(42):n/a-n/a. doi:10.1002/anie.201406466.

18. Berhe TA, Su W-N, Chen C-H, et al. Organometal halide perovskite solar cells: degradation and stability. Energy Environ. Sci. 2016;9(2):323-356. doi:10.1039/C5EE02733K.

19. Williams ST, Rajagopal A, Chueh C-C, Jen AK-Y. Current Challenges and Prospective Research for Upscaling Hybrid Perovskite Photovoltaics. J. Phys. Chem. Lett. 2016;7(5):811-819. doi:10.1021/acs.jpclett.5b02651.

20. Noh JH, Im SH, Heo JH, Mandal TN, Seok SIS II. Chemical Management for Colorful, Efficient, and Stable Inorganic-Organic Hybrid Nanostructured Solar Cells. Nano Lett. 2013;13(4):1764-1769. doi:10.1021/nl400349b.

21. Aristidou N, Sanchez-Molina I, Chotchuangchutchaval $\mathrm{T}$, et al. The Role of Oxygen in the Degradation of Methylammonium Lead Trihalide Perovskite Photoactive Layers. Angew. Chemie Int. Ed. 2015;54(28):8208-8212. doi:10.1002/anie.201503153.

22. Bryant D, Aristidou N, Pont S, et al. Light and oxygen induced degradation limits the operational stability of methylammonium lead triiodide perovskite solar cells. Energy Environ. Sci. 2016;9(5):1655-1660. doi:10.1039/C6EE00409A.

23. Bannock JH, Treat ND, Chabinyc M, Stingelin N, Heeney M, de Mello JC. The influence of polymer purification on the efficiency of poly(3hexylthiophene):fullerene organic solar cells. Sci. Rep. 2016;6(October 2015):23651. doi:10.1038/srep23651. 24. Ruess R, Benfer F, Boecher F, et al. Stabilization of 
Organic-Inorganic Perovskite Layers by Partial Substitution of lodide by Bromide in Methylammonium Lead lodide. ChemPhysChem 2016;17(10):15051511. doi:10.1002/cphc.201501168.

25. Wang S, Jiang Y, Juarez-Perez EJ, Ono LK, Qi Y. Accelerated degradation of methylammonium lead iodide perovskites induced by exposure to iodine vapour. Nat. Energy 2016;2(1):16195.

doi:10.1038/nenergy.2016.195.

26. McMeekin DP, Sadoughi G, Rehman W, et al. A mixed-cation lead mixed-halide perovskite absorber for tandem solar cells. Science (80-. ). 2016;351(6269):151-155. doi:10.1126/science.aad5845.

27. Domanski K, Correa-Baena J-P, Mine N, et al. Not All That Glitters Is Gold: Metal-Migration-Induced Degradation in Perovskite Solar Cells. ACS Nano 2016;10(6):6306-6314.

doi:10.1021/acsnano.6b02613.

28. Hoke ET, Slotcavage DJ, Dohner ER, et al. Reversible photo-induced trap formation in mixed-halide hybrid perovskites for photovoltaics. Chem. Sci. 2015;6(1):613-617. doi:10.1039/C4SC03141E.

29. Zhang $Y-Y$, Chen S, Xu P, et al. Intrinsic Instability of the Hybrid Halide Perovskite Semiconductor CH3NH3Pbl3. 2015:11. Available at: http://arxiv.org/abs/1506.01301. Accessed March 17, 2016. 